\title{
Respon Masyarakat Terhadap Keberadaan Pasar Kaget Rawasari Jakarta Pusat
}

\author{
Bella Mareta Thania ${ }^{1}$, Kartika Sahar ${ }^{2}$, Pramesti Eka Braniati ${ }^{3}$, *Dedi Hantono ${ }^{4}$ \\ Program Studi Arsitektur, Fakultas Teknik, Universitas Muhammadiyah Jakarta \\ dedihantono@umj.ac.id
}

*Alamat korespondensi, Masuk: 27 Februari 2020, Direvisi: 10 Maret 2020, Diterima: 10 April 2020

\begin{abstract}
ABSTRAK: Pasar Kaget merupakan pasar yang keberadaannya hanya diwaktu-waktu tertentu pada lokasi yang ramai pengunjung. Di daerah Rawasari, Jakarta Pusat, terdapat fenomena keberadaan pasar kaget ditengah permukiman warga dan bersebelahan dengan pasar tradisional yang buka setiap hari. Keberadaaan pasar kaget tersebut dapat mempengaruhi perkembangan lingkungan sekitarnya. Tujuan dari penelitian ini untuk mengetahui respon masyarakat terhadap keberadaan pasar kaget serta dampaknya terhadap perkembangan lingkungan sekitar. Penelitian ini menggunakan metode kualitatif dengan melakukan survey primer melalui studi pustaka, observasi, dan wawancara. Hasil penelitian menunjukkan bahwa masyarakat merespon positif keberadaan pasar kaget karena dapat membantu mereka terhadap kebutuhan sehari-hari dan lokasi yang strategis terhadap pemukiman sekitar. Hal ini dapat dilihat dari antusiasme warga yang ramai berbelanja.
\end{abstract}

Kata kunci: Respon masyarakat, pasar kaget, pasar tradisional.

\begin{abstract}
Seasonal Market is a market that only exists at certain times in a busy location. In the Rawasari area, Central Jakarta, there is a phenomenon of the existence of a seasonal market in the middle of residential areas and adjacent to a traditional market that is open every day. The existence of the seasonal market can influence the development of the surrounding environment. The purpose of this study was to determine the public response to the existence of a seasonal market and its impact on the development of the surrounding environment. This research uses qualitative methods by conducting a primary survey through literature study, observation, and interview. The results showed that the community responded positively to the existence of a seasonal market because it could help them with their daily needs and strategic location of the surrounding settlements. This can be seen from the enthusiasm of residents who are busy shopping.
\end{abstract}

Keywords: Society response, seasonal market, traditional market

\section{PENDAHULUAN}

Respon merupakan pandangan dari masyarakat terhadap hal yang diterima dari panca inderanya baik yang bersifat positif maupun negatif. Respon dihasilkan ketika seseorang telah melihat dan merasakan objek tertentu sehingga dapat dikatakan respon saling berkaitan sebab akibat antara fenomena yang terjadi di lingkungan dengan perilaku masyarakat yang ada di sekitarnya [1]. Respon juga dapat diartikan sebagai media dalam berkomunikasi terhadap sesuatu yang dipasarkan pada saat menerima sesuatu. Respon pada prosesnya didahului oleh sikap seseorang, karena sikap merupakan kecendrungan atau kesediaan seseorang untuk bertingkah laku dalam menghadapi suatu rangsangan tertentu. Jadi sikaplah yang menentukan seseorang merespon atau tidak merespon terhadap sesuatu yang diterimanya [2].
Pasar kaget merupakan pasar tradisional yang memiliki waktu dan tempat tertentu pada suatu lingkungan. Hal ini didukung dalam penelitian (Tri Tarwiyan, Arnesih, 2017) yang mengatakan bahwa Pasar kaget adalah salah satu bentuk dari pasar tradisional, hal itu disebabkan karena pasar ini buka hanya sesaat, tiba-tiba dan dapat hanya diwaktu-waktu tertentu saja. Berbagai manfaat yang dirasakan oleh masyarakat menjadi salah satu faktor adanya pasar kaget. Hal ini juga dikarenakan dapat mempertahankan nilai-nilai tradisional dalam berbelanja yaitu transaksi langsung antara penjual dengan pembeli [3]. Pasar kaget juga sebagai tempat terjadinya aktivitas penjual dan pembeli secara langsung sesuai dengan waktu dan tempat yang telah ditentukan. Pasar kaget memiliki struktur ruang yang kuno dan fungsi yang masih konvensional, seperti: sistem pembayaran yang 
masih menggunakan uang tunai dan terjadinya proses tawar-menawar [4]. Pada pasar moderen sistem jual-beli tersebut sudah jarang ditemui. Pada pasar moderen sistem jual beli cenderung berjalan dengan cepat sedangkan jika pada pasar tradisional proses jual beli juga diikuti dengan interaksi sosial antara penjual dan pembeli yang membutuhkan waktu yang cukup lama [5]. Lalu, untuk struktur ruang yang kuno maksudnya adalah tata letak barang untuk diperjualbelikan diletakkan secara acak atau tidak disusun berdasarkan kelompok tertentu sedangkan pada pasar modern barang-barang yang dijual dikelompokkan berdasarkan kategori tertentu, contoh: pemisahan area-area untuk sayur-mayur, daging-dagingan, dan lain-lain disusun berdarkan kelompoknya.

Fenomena pasar kaget merupakan wujud usaha informal yang membentuk ruang informal dan sangat diminati hampir seluruh kalangan masyarakat karena berdasarkan pertimbangan faktor lokasi, aksesibilitas, mobolitas, dan konektivitas sehingga memenuhi aspek ekonomis [6] walaupun memiliki tingkat keamanan yang rendah [7]. Pada pasar kaget diperjualbelikan beraneka barang dagangan, seperti: kebutuhan rumah tangga sehari-hari. Pasar kaget dapat menjadi tempat bagi pedagang kecil untuk bersaing dengan pedagang yang berskala besar [8]. Oleh karena itu perlu meneliti respon masyarakat terhadap keberadaan pasar kaget agar dapat mengetahui peyebab perkembangan pasar kaget serta dampak yang ditimbulkan dalam lingkungan masyarakat.

\section{METODE PENELITIAN}

Dalam penelitian ini menggunakan metode deskriptif kualitatif. Metode kualitatif untuk menguji teori-teori yang digunakan dengan data dan fakta yang ditemukan pada saat observasi. Metode pengumpulan data dilakukan dengan survei primer melalui studi pustaka, observasi lapangan, dan wawancara, studi pustaka, dan dokumentasi. Metode observasi dilakukan untuk mengetahui kondisi pasar kaget di Rawasari. Metode wawancara dilakukan untuk mengetahui respon dari masyarakat sekitar pasar kaget dengan teknik pengambilan data berupa pengamatan, dokumentasi, dan wawancara singkat dengan pedagang dan pembeli.

\section{HASIL DAN PEMBAHASAN}

\section{Gambaran Umum Objek Penelitian.}

Penelitian dilakukan di kawasan Pasar Rawasari. Pasar Rawasari merupakan pasar tradisional yang berlokasi di Jalan Rawasari Selatan, Jakarta Pusat. Pasar Rawasari merupakan pasar yang menjual berbagai kebutuhan pangan berupa sembako. Pasar ini berada di Selatan RSUD Cempaka Putih dan Timur Pusat Pengembangan dan Pelatihan KB, Pusat Pemberdayaan Perempuan dan Perlindungan anak (Pusbanglat KB,PP dan PA).

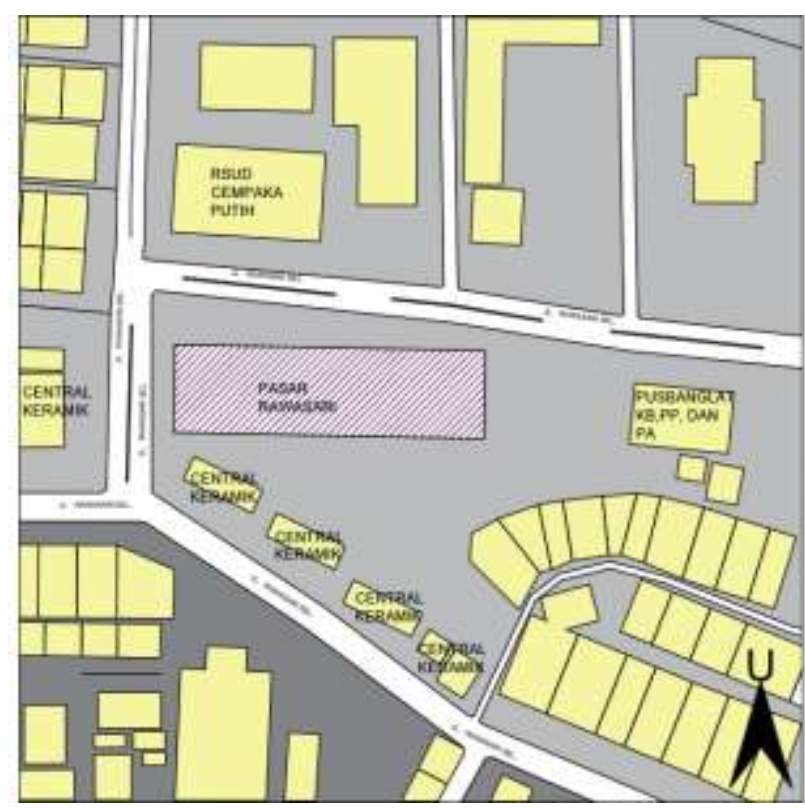

Gambar 1. Kawasan Pasar Rawasari

Sumber: penulis, 2019

\section{Kondisi Pasar Rawasari.}

Pasar Rawasari merupakan pasar tempat menjual bahan pangan (sembako) yang berlangsung setiap hari dari pagi hingga sore hari. Kondisi Pasar Rawasari cukup ramai karena berada di sekitar bangunan umum, seperti fasilitas kesehatan, kantor pemerintah, pusat penjualan bahan bangunan, dan pemukiman. Akses jalan menuju Pasar Rawasari menggunakan sistem 2 arah sehingga cukup mudah dijangkau. Selain menggunakan kendaraan pribadi terdapat pula angkutan umum menuju pasar ini. Situasi ini bisa dilihat pada gambar 2. Pada gambar tersebut digambarkan bahwa akses kendaraan bermotor berupa panah berwarna merah dan akses pejalan kaki berupa garis berwarna biru. 


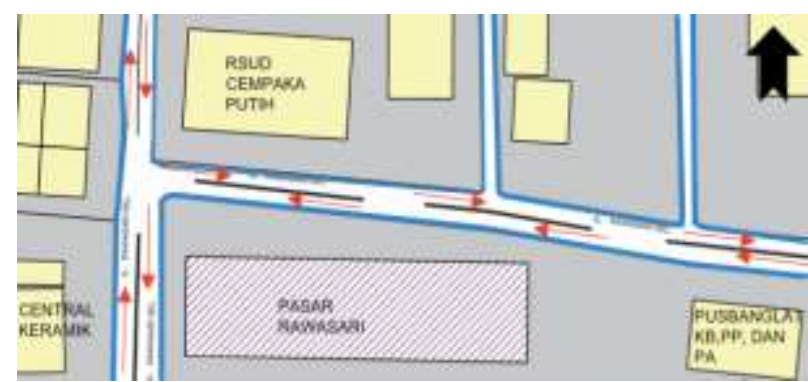

Gambar 2. Sirkulasi sekitar kawasan Pasar Rawasari

Sumber: penulis, 2019

\section{Faktor-Faktor Pemicu Keberadaan Pasar Kaget}

Pasar Rawasari merupakan pasar tradisional yang dikelola oleh pemerintah. Pada sisi Utara Pasar Rawasari terdapat pasar kaget yang buka setiap hari Sabtu dan Minggu pukul 07.00-13.00 WIB. Pasar kaget ini merupakan pasar informal yang dikelola secara swadaya. Mereka menjual barang-barang elektronik, pakaian, peralatan rumah tangga dan mainan anak-anak.

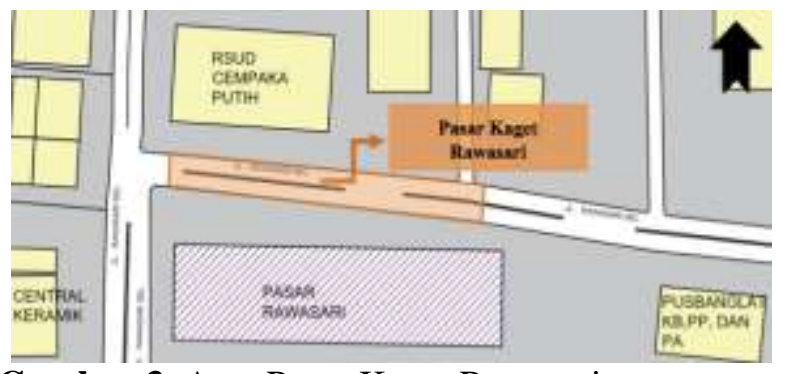

Gambar 3. Area Pasar Kaget Rawasari

Sumber: penulis, 2019

Menurut Umaya selaku konsumen pasar kaget (wawancara, Oktober 2019) keberadaan Pasar Kaget Rawasari menjadi alternatif warga dalam memenuhi kebutuhan, khususnya selain kebutuhan pangan. Umaya juga mengatakan bahwa Pasar Kaget Rawasari merupakan pasar yang dikelola oleh perorangan sehingga barang-barang yang dijual ditawarkan dengan harga murah. Terdapat beberapa faktor lain menurut Imam selaku salah satu pedagang kaki lima di Pasar Kaget Rawasari yaitu :

1. Adanya lokasi yang strategis yaitu berada di sekitar area RSUD Cempaka Putih dan area pasar tradisional yang ramai pengunjung.

2. Adanya area terbuka yang mudah di akses oleh warga namun merupakan area yang jarang dilalui kendaraan bermotor.

3. Peluang dalam memenuhi kebutuhan warga dengan menjual barang-barang yang tidak ada di Pasar Rawasari, seperti: peralatan rumah tangga, pakaian, mainan anak dan adanya pedagang kaki lima. Sehingga menarik perhatian warga.

\section{Kondisi Pasar Rawasari Saat Adanya Pasar Kaget.}

Kondisi pasar Rawasari saat adanya pasar kaget semakin menjadi lebih ramai, terlebih lagi pada saat hari Sabtu dan Minggu. Menurut pengamatan, pasar kaget lebih ramai pada pagi hari dibandingkan siang hari. Menurut konsumen pasar kaget yang berhasil diwawancarai di lokasi bahwa harga yang ditawarkan di pasar kaget relatif lebih murah dibandingkan dengan pasar lainnya sehingga masyarakat sangat menerima keberadaan pasar kaget di lingkungannya.

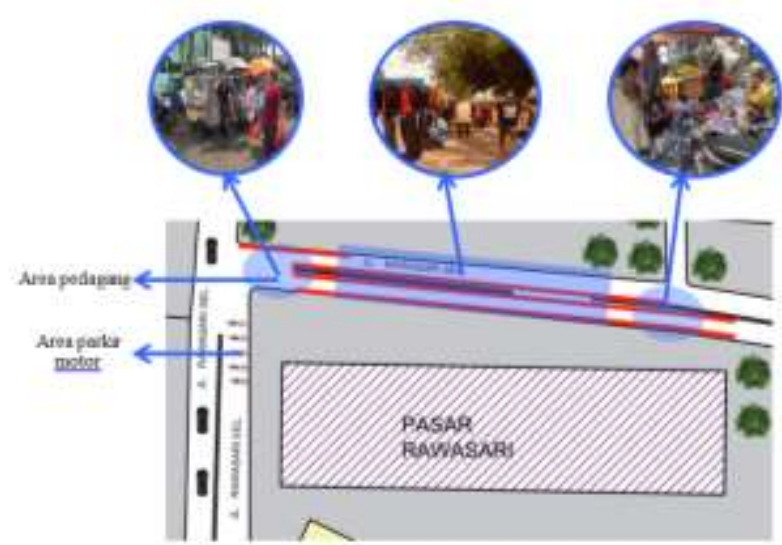

Gambar 4. Kondisi Pasar Rawasari pada jam 6 sampai 9 pagi

Sumber : penulis, 2019

Gambar 4 menunjukkan hasil pengamatan berdasarkan analisa pengamat mengenai kondisi Pasar Rawasari dan pasar kaget. Pada kedua ujung pasar kaget pedagang berjualan makanan sedangkan pada bagian tengah berjualan pakaian, perabot rumah tangga, dan lain-lain. Satu jam sebelum pasar kaget mulai operasional, para pedagang sudah mempersiapkan lapak dan menyusun barang dagangannya. Keramaian ini berlanjut hingga jam 9 pagi karena sudah mulai datangnya para pembeli. 


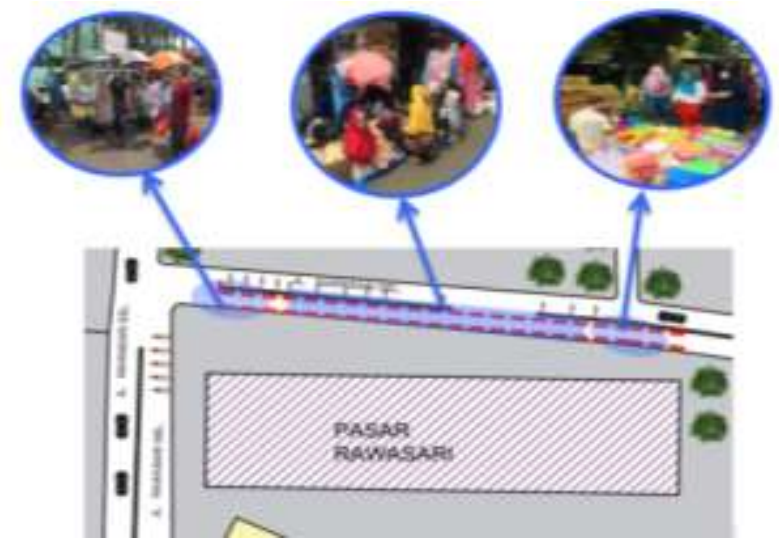

Gambar 5. Kondisi pasar Rawasari pada jam 9 sampai 11 pagi

Sumber: penulis, 2019

Keramaian pasar kaget berangsur berkurang dari jam 9 pagi hingga jam 11 siang karena pembeli yang sudah semakin sedikit yang datang dan lebih banyak yang pulang. Garis merah terputus-putus pada gambar menjelaskan bahwa para pedagang sudah mulai pergi. Pada salah satu ujung pasar menjadi tempat parkir motor karena beberapa pedagang disana sudah menutup aktivitasnya.

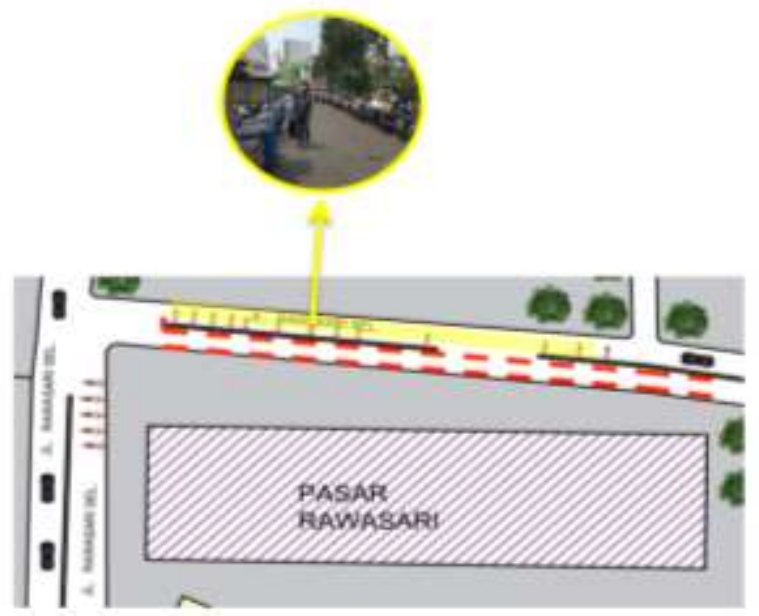

Gambar 6. Kondisi pasar Rawasari pada jam 11 sampai 1 siang.

Sumber: penulis, 2019

Kondisi pasar saat jam 11 sampai 1 siang pada gambar garis merah yang terputus-putus yang jarang menggambarkan para pedagang sudah mulai sepi karena sudah pasar sudah hampir tutup, pada salah satu jalan yang pada pagi hari untuk para pedagang menjajakan barang dagangannya digantikan dengan parkiran untuk motor.

\section{Dampak Adanya Pasar Kaget.}

Keberadaan pasar kaget tentu memiliki dampak terhadap penjual, pembeli serta lingkungan yang berada di sekitar pasar kaget tersebut. Dampak yang ada merupakan hal yang akan menimbulkan respon dari masyrakat yang berada di sekitar Pasar Kaget tersebut. Dampak yang timbul dari adanya pasar kaget yaitu dampak positif dan dampak negatif. Beberapa dampak positif dari adanya pasar kaget yaitu :

1. Aksesibilitas mudah dan terjangkau

Pembeli memiliki akses yang mudah menuju pasar kaget karena dekat dengan pemukiman. Radius yang dimiliki antara tempat pemukiman dan tempat pasar kaget kurang lebih 8meter sampai 10 meter. Sehingga dengan jarak radius yang ada masih memudahkan konsumen dalam mencapai lokasi pasar kaget. Pada Gambar 7 terlihat adanya pola yang bersinggungan yang menandakan bahwa radius atau jarak pasar kaget dengan pemukiman masih mudah dicapai.

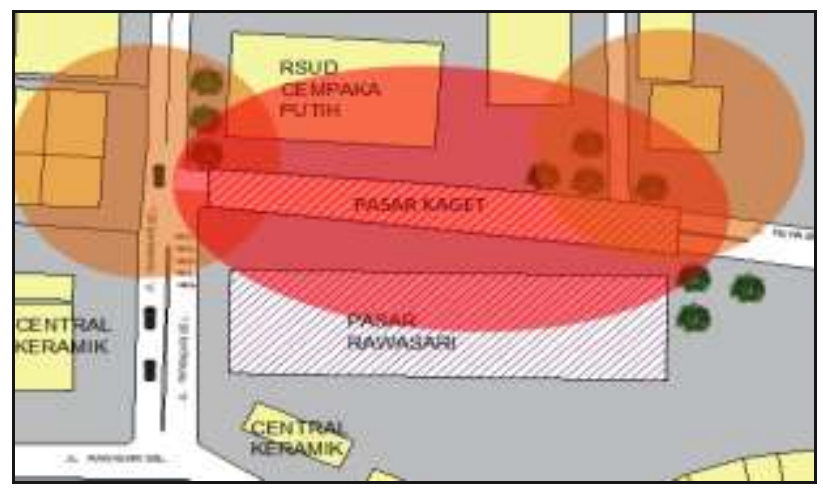

Gambar 7. Radius Pencapaian Menuju Pasar Kaget Rawasari

Sumber: penulis, 2019

2. Memenuhi kebutuhan pangan dan sandang bagi konsumen

Pembeli dapat memenuhi kebutuhan pangan dan sandang secara bersamaan, karena terdapat akses yang mudah dari pasar rawasari yang menjual kebutuhan pangan dengan pasar kaget yang menjual kebutuhan sandang. Pada Gambar 8 dijelaskan bahwa tanda panah mengarah sebagai jalur sirkulasi antara pasar Rawasari dengan Pasar Kaget yang berada di belakang Rawasari. 


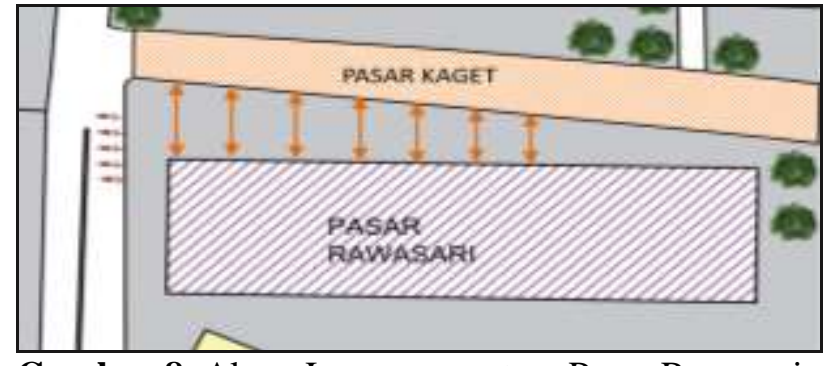

Gambar 8. Akses Langsung antara Pasar Rawasari dengan Pasar Kaget Rawasari

Sumber: penulis, 2019

\section{Terciptanya kegiatan sosial bagi konsumen}

Meningkatkan kegiatan sosialisasi karena adanya tempat rekreasi dan ruang komunal. Hal ini tercipta karena adanya kegiatan pasar kaget yang memicu munculnya ruang-ruang yang dibutuhkan bagi masyarakat sekitar lokasi pasar kaget yang dapat menarik minat pengunjung atau konsumen pasar kaget.

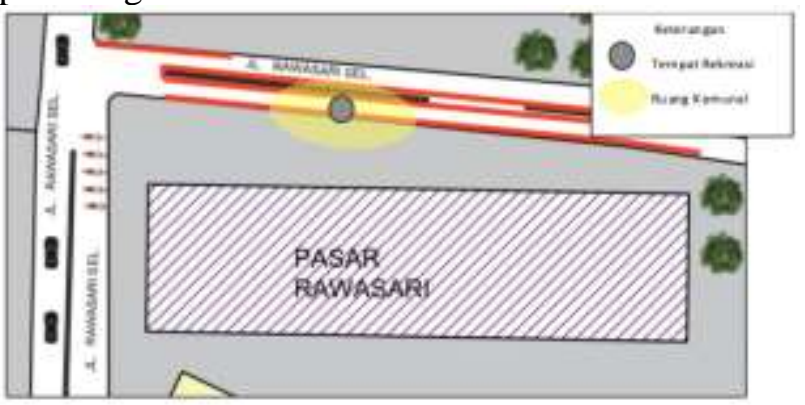

Gambar 9. Akses Langsung antara Pasar Rawasari dengan Pasar Kaget Rawasari

Sumber : penulis, 2019

Pada keberadaan pasar kaget terdapat dampak negatif, yaitu: meningkatkan kepadatan sirkulasi di beberapa ruas jalan umum sehingga menimbulkan kemacetan dan berbahaya karena sirkulasi antara kendaraan dengan manusia yang hampir saling bersinggungan.

1. Kondisi Pasar Kaget pada Pagi Hari

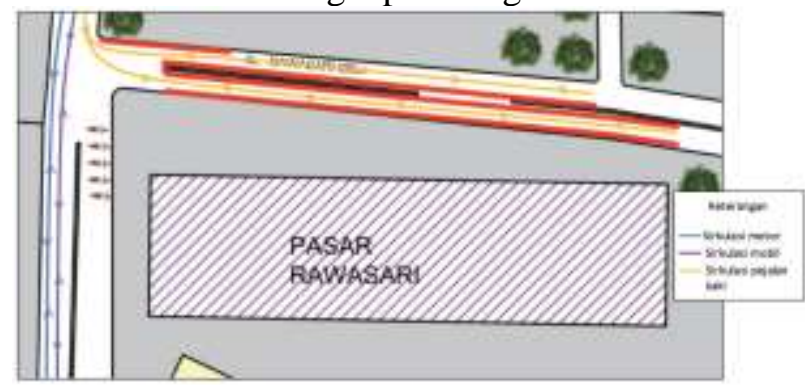

Gambar 10. Sirkulasi pasar Rawasari pada jam 6 sampai 9 pagi

Sumber: penulis, 2019
Pada pagi hari Pasar Kaget Rawasari masih dipenuhi oleh pedagang. Sirkulasi pada jalan Rawasari pada kondisi tersebut hanya diperuntukkan bagi pembeli atau pejalan kaki saja sehingga untuk sirkulasi kendaraan bermotor tertutup dengan adanya aktivitas jual beli pasar tersebut sehingga pengguna jalan harus menggunakan jalan alternatif lain jika ingin menuju jalan utama.

2. Kondisi Pasar Kaget pada jam 9 sampai jam 11

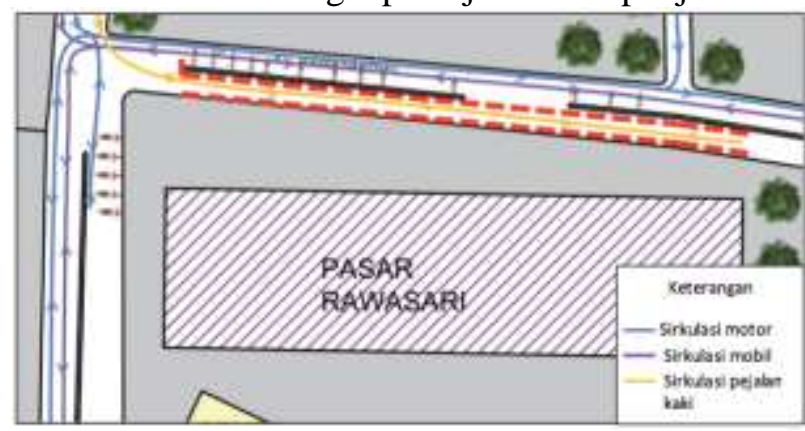

Gambar 11. Sirkulasi pasar Rawasari pada jam 9 sampai 11 pagi

Sumber: penulis, 2019

Pada pagi sekitar jam 9 sampai jam 11, pedagang pada pasar kaget sudah mulai berkurang. Para pengguna kendaraan bermotor sudah bisa mengakses jalan Rawasari, namun dipinggir jalan tersebut masih digunakan sebagai tempat parkir bagi pembeli. Hal tersebut menyebabkan terhambatnya sirkulasi pengguna kendaraan bermotor. Seringkali timbul kemacetan pada jalan tersebut ketika terdapat dua mobil yang ingin mengakses jalan dari dua arah yang berlawanan.

3. Kondisi Pasar Kaget pada jam 11 sampai jam 1 siang

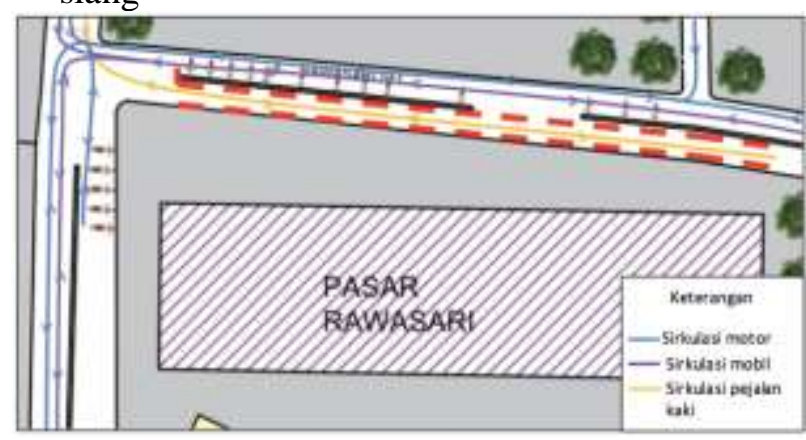

Gambar 12. Sirkulasi pasar Rawasari pada jam 11 sampai 1 siang.

Sumber: penulis, 2019

Pada jam 11.00 hingga 13.00 WIB pedagang pasar sudah semakin berkurang, namun kondisi sirkulasi pada jalan Rawasari masih tetap sama. Para pembeli masih tetap menggunakan jalan 
Rawasari sebagai tempat parkir motor dan menyebabkan terhambatnya sirkulasi kendaraan pada jalan tersebut.

\section{KESIMPULAN}

Berdasarkan pembahasan yang telah diuraikan maka dapat disimpulkan bahwa masyarakat merespon dengan baik terhadap keberadaan pasar kaget di Rawasari, terlihat dari antusiasme masyarakat yang menyukai berbelanja di pasar kaget tersebut. Hal tersebut dikarenakan pasar kaget dapat menyediakan barang-barang dengan harga lebih murah bagi pembeli dan juga sebagai sarana lokasi berjualan yang strategis bagi penjual. serta jarak tempuh yang relatif dekat dari permukiman warga. Dari hal ini diharapkan banyak pembeli yang menggunakan moda mobilitas dengan berjalan kaki sehingga meningkatkan kualitas lingkungan dan kontak sosial antar sesama warga.

Selain dampak positif terdapat juga dampak negatif yang ditimbulkan diantaranya terjadinya kemacetan saat pasar kaget berlangsung. Hal ini disebabkan tidak tersedianya lahan parkir yang memadai dan perilaku pembeli yang tidak tertib dalam melakukan proses transaksi jual beli di pasar kaget tersebut. Untuk itu perlu disediakan area parkir yang bisa menggunakan lahan di ujung Timur kawasan. Untuk mengkases lahan tersebut pedagang bisa memundurkan lapaknya demi memberi ruang sirkulasi dan akses ke area parkir yang akan disediakan.

\section{DAFTAR PUSTAKA}

[1] Syahrier FA (2015) Respon Masyarakat Terhadap Keberadaan Pasar Kaget Di Kelurahan Tuah Karya Kecamatan Tampan Kota Pekanbaru. Studi pada Pasar Kaget Riau Indah Lestari Kelurahan Tuah Karya Kecamatan Tampan Kota Pekanbaru Tahun 2014. Jurnal Online Mahasiswa Bidang Ilmu Sosial dan Ilmu Politik Vol. 2, No. 1: Hal. $1-11$.

[2] Setiawan IB, and Bahri S (2017) Respon Masyarakat Terhadap Pembangunan Jalan Kereta Api Di Desa Bagan Sinembah Kota Kecamatan Bagan Sinembah Kabupaten Rokan Hilr. Journal Of Chemical Information And Modeling Vol. 53, No. 9: Hal. 1689-1699.

[3] Tarwiyani T, Arnesih A, and Hutagaol NM (2017) Fenomena Pasar Kaget Di Kota Batam Tahun 1980-2015 (Sebuah Tinjauan Historis). Jurnal Dimensi Vol. 6, No. 1: Hal. 48-62.

[4] Ayumas Widya Sari LP (2017) Eksternalitas Penggunaan Ruang Publik sebagai Pasar Kaget (Pop-up Market) bagi Masyarakat Dewasa Muda Kota Bandung. Dipresentasikan pada Temu Ilmiah Ikatan Peneliti Lingkungan Binaan Indonesia (IPLBI), Vol. 6.

[5] Hantono D, Butudoka Z, Prakoso AA, and Yulisaksono D (2019) Adaptasi Seting Ruang Pasar Jiung Terhadap Kehadiran Pasar Temporer Di Jalan Kemayoran Gempol Barat Jakarta. Jurnal Arsitektur Zonasi Vol. 2, No. 2: Hal. 75-87.

[6] Prayitno B (2017) Sustainable Resilience of Vulnerable Urban Kampong Fisherman Settlement in Dadap, Indonesia. Dipresentasikan pada HABITechno 3 International Conference; Bandung: Institut Teknologi Bandung.

[7] Pramitasari D, and Sarwadi A (2015) A Study on Elderly's Going Out Activities and Environment Facilities. Dipresentasikan pada Procedia Environmental Sciences, Vol. 28, Hal. 315-323.

[8] Putri A (2017) Karakteristik lokasi restoran Korea di Kota Depok (Location characteristic of Korean restaurant in Depok City). Jakarta. Universitas Indonesia. 